\title{
Laser-induced breakdown spectroscopy applied to the evaluation of penetration depth in limestones of bactericidal treatments based on silver nanoparticles
}

\author{
Maripaz Mateo ${ }^{1}$, Javier Becerra², Ana Paula Zaderenko², Pilar Ortiz ${ }^{2}$, Ginés Nicolás ${ }^{1}$ \\ ${ }^{1}$ Departamento de Ingeniería Naval e Industrial, Laser Applications Laboratory, Universidade da \\ Coruña, C/ Mendizabal s/n, 15403 Ferrol, Spain \\ ${ }^{2}$ Departamento de Sistemas Físicos, Químicos y Naturales, Universidad Pablo de Olavide, Ctra. \\ de Utrera Km.1, ES-41013, Seville, Spain
}

Corresponding author: Tel.: +34 881013274; fax: +34 981337410. E-mail address: gines@udc.es (G. Nicolas)

\begin{abstract}
In this work, laser induced breakdown spectroscopy (LIBS) technique has been tested for the indepth characterization of new nanoparticles to be employed in heritage buildings for protective purposes.

In particular, a biocidal treatment based on silver nanoparticles applied to limestones from Utrera's quarry (Seville, Spain), commonly employed in historical buildings in the south of Spain, has been analysed in this study. This nanomaterial is known to be an effective protection against bacteria development, but its assessment depends on the in-depth penetration of the particles. For this reason, LIBS depth profiling has been used to characterize the location of this nanomaterial in the matrix and to determine its penetration depth with the aim of controlling the treatment process.

The characteristic emission peak of $\mathrm{Ag}(\mathrm{I})$ at $338.289 \mathrm{~nm}$ has been successfully identified in the LIBS spectra of the treated sample, demonstrating the capability of LIBS technique for the detection of silver nanoparticles in limestone. In addition, LIBS depth profiles have been generated to characterize the diffusion of this nanomaterial in the matrix. From the LIBS indepth analyses of the sample under study, the penetration of the silver bactericidal treatment in the Utrera's quarry limestone slab has been estimated as $130-230 \mu \mathrm{m}$. These results demonstrate the capability of LIBS technique for the in-depth analysis of the silver nanoparticles and they provide a very useful information for the characterization of the biocidal treatments effectiveness.
\end{abstract}

\section{Keywords}

LIBS, in-depth analysis, silver nanoparticles, biocide, limestone treatment, construction materials 


\section{Introduction}

The development of new treatments based on nanomaterials is one of the most important scientist contributions in the restoration field. However, the fast introduction of this typology of materials in the restoration processes sometimes carries out deficiencies in their application methods and the evaluation of their effectiveness. For that reason, it is important to develop diagnosis techniques which allow us the study of these treatments in both laboratory assays and on site applications.

One of the most interesting new treatment based on nanoparticles is the use of metallic nanoparticles, especially as inhibiting agents for microorganism growth and biopatina formation in stone monuments [1-5]. Among these promising nanomaterials, it is worth highlighting the silver nanoparticles whose bactericidal properties have been corroborated by various authors $[6,7]$ and explored in different fields such as medicine, cosmetics, textile industry or environmental remediation [8].

A new restoration treatment must be effective, not modify the aesthetic values or damage the original material. In this research, the treatment proposed is based on silver nanoparticles which are inorganic as the original material used in the construction of historical buildings. These nanoparticles have been dispersed in a harmless and non-toxic solvent for man or environment (water) [9]. The aesthetic compatibility of the treatment was analysed in previous studies $[10,11]$ by colorimetry, a common technique used to detect the colour variation between the state before and after the treatment $[12,13]$. However, the penetration of this biocide treatment based on nanoparticles is not usually measured. The effectiveness of this type of treatments depend on if the nanoparticles reach the same depth that the microorganism colonies to inhibit them. Traditionally, scanning electron microscopy with X-rays dispersive energies (SEM-EDX) have been used for this purpose $[14,15]$, but the main disadvantage of this technique is that it requires the sampling and its laboratory analysis. Laser spectroscopy based on material ablation (LIBS) is a technique that allows the qualitative and quantitative chemical analysis depending on the atomic emission that is produced in the plasma generated by the impact of a high intensity pulse laser beam. This technique has already been used in different heritage studies [16-22], and it is remarkable its recent use for determining the stratigraphic sequence of artworks [23]. Regarding LIBS technique related to nanoparticles, a recent trend employs nanoparticles to enhance LIBS intensity because the presence of nanoparticles involved in the ablation process enhances the detected signal and therefore improves the analytical sensitivity of the technique [24-26]. On the other hand, LIBS has been used for the successfully analysis of nanoparticles in different fields like the analysis of biological tissues [27], on-line industrial monitoring $[28,29]$ or pharmaceutical quality control [30].

In this research, LIBS technique is proposed for the first time to analyse the penetration depth of the nanoparticles employed in biocidal treatments of historical buildings, with the advantages of being a minimally invasive technique that does not require sampling nor previous sample preparation and being able to perform on site analysis if needed [31,32]. In addition, LIBS technique allows to perform the analysis in the desired location of the sample and to generate associate depth profiles which can be used to study the diffusion of the nanoparticles in the matrix and to determine the penetration depth achieved by the protective treatment. The 
present study has been carried out on limestone samples previously treated by a biocidal treatment based on silver nanoparticles. These nanoparticles have been stabilized with citrate, obtaining a good stability in suspension and a small hydrodynamic diameter. Thereby, through the use of LIBS technique it has been possible the in-depth characterization of the biocidal treatment and the measurement of its penetration depth in order to evaluate the effectiveness of the nanomaterials for protective purposes.

\section{Materials and Methods}

\subsection{Synthesis and application of silver-based bactericidal treatments on stone samples}

Materials. Silver nitrate $\left(\mathrm{AgNO}_{3}\right)$ and trisodium citrate were purchased from Panreac and sodium borohydride $\left(\mathrm{NaBH}_{4}\right)$ from Sigma-Aldrich. All other chemicals were reagent grade. Water was purified using a Milli-Q reagent grade water system from Millipore.

Synthesis. A biocidal treatment based on silver nanoparticles stabilized by citrate (AgNps) was synthesized. For that purpose, silver nanoparticles were prepared by reduction of $\mathrm{AgNO}_{3}$ with $\mathrm{NaBH}_{4}$ in aqueous medium, and stabilized by trisodium citrate according to Flores et al. [33]. Briefly, $1 \mathrm{~mL}$ of an aqueous solution of $\mathrm{AgNO}_{3}(5 \mathrm{mM})$ was added to $16 \mathrm{~mL}$ of an aqueous solution of trisodium citrate $(1.06 \mathrm{mM})$ under magnetic stirring in an ice bath. Then, $100 \mu \mathrm{L}$ of an aqueous solution of $\mathrm{NaBH}_{4}(100 \mathrm{mM})$ were added dropwise to the mixture and the final solution was stirred for $1 \mathrm{~h}$ and $45 \mathrm{~min}$. The resulting suspension was kept in darkness until being applied on stone samples.

AgNPs were characterized by UV-Visible (UV-Vis) spectrophotometry, Dynamic Light Scattering (DLS) and Raman spectroscopy. UV-Vis spectra were recorded on an Ocean optics spectrometer equipped with a HR4000 detector (Dunedin, FL. USA). Zeta potential (Z) and hydrodynamic diameter (HD) were determined by DLS on a Zetatrac Analyzer (Microtrac, USA). Raman spectra were recorded on a Bruker Senterra confocal Raman microscope equipped with a laser excitation of $785 \mathrm{~nm}$ and a DU420A-OE-152 detector.

Stone samples. Limestone slabs $(1.5 \times 1.5 \times 0.5 \mathrm{~cm})$ were employed as experimental specimens because this stone has been one of the most commonly used in the construction of historical buildings. Additionally, the quarry of Utrera (Seville, Spain) was chosen as the source of the slabs because it is one of the most relevant quarries in southern Spain, and the limestone from this quarry has been used in historical buildings as important as the Cathedral [34] or the Town Hall [35] of Seville. This limestone is a carbonated bioclastic limestones with a high content of quartz and fossil material, an open porosity of about $10 \%$ with a high intra-porosity not connected and an average pore diameter between 0.1 and $1 \mu \mathrm{m}[35,36]$.

Application of the treatment on stone samples. $200 \mu \mathrm{L}$ of an aqueous suspension of AgNps at $0.03 \mathrm{mg} / \mathrm{mL}$ was deposited on the surface of a stone slab, and it was allowed to dry at room temperature $\left(24^{\circ} \mathrm{C} \pm 2\right)$. 


\subsection{Penetration of the treatment on stone matrices}

The experimental arrangement used for the in-depth characterization of the silver nanoparticles has been a typical single pulse LIBS setup. In this work, a Q-Switched Nd:YAG laser (Brilliant, Quantel, $5 \mathrm{~ns}$ pulse width) working at the second harmonic wavelength of $532 \mathrm{~nm}$ has been used to perform the LIBS analyses. The laser beam has been focused at normal incidence onto the sample surface by a plano-convex quartz lens $(f=100 \mathrm{~mm})$ to achieve the necessary energy density to ablate the sample and produce the plasma. The plasma radiation has been guided by means of a quartz optical fiber to the entrance slit of an Echelle spectrograph (Mechelle, Andor) where the plasma light is dispersed and directed to an ICCD camera (iStar, Andor) where it is detected. The spectral region covers from 200 to $850 \mathrm{~nm}$. The pulse energy has been set at $27 \mathrm{~mJ}$. A time delay of $2.5 \mu \mathrm{s}$ and an integration time of $10 \mu \mathrm{s}$ have been used for the data acquisition. The LIBS measurements have been performed in air under atmospheric pressure.

\section{Results and discussion}

\subsection{Synthesis and characterization of the treatment}

Citrate-stabilized silver nanoparticles (AgNps) have been selected to evaluate their penetration into stone matrices and their possible use as biocide treatment of historic buildings. This treatment was applied on stone slabs as an aqueous solution. AgNps form a pale-yellow colloid with a hydrodynamic diameter (HD) of $36 \pm 8 \mathrm{~nm}$ and a Zeta potential (द) of $-63 \pm 3 \mathrm{mV}$. Its small particle size and remarkably high $\zeta$ is in keeping with high colloidal stability and good long-term stability [37].

As can be seen in the UV-Vis spectra (Fig. 1A) AgNps show a narrow surface plasmon peaking at $400 \mathrm{~nm}$, which indicates that these silver nanoparticles are small, stable and have a narrow size distribution [38]. On the other hand, the Raman characterization confirms the presence of the expected band (Fig. 1B). Despite the metallic Ag cannot be detected by Raman spectroscopy [39], it is possible to detect it indirectly by the interaction with other materials. In fact, AgNps scattering spectrum shows a strong band at $240 \mathrm{~cm}^{-1}$ due to the stretching vibrations of Ag-O bonds $[40,41]$.

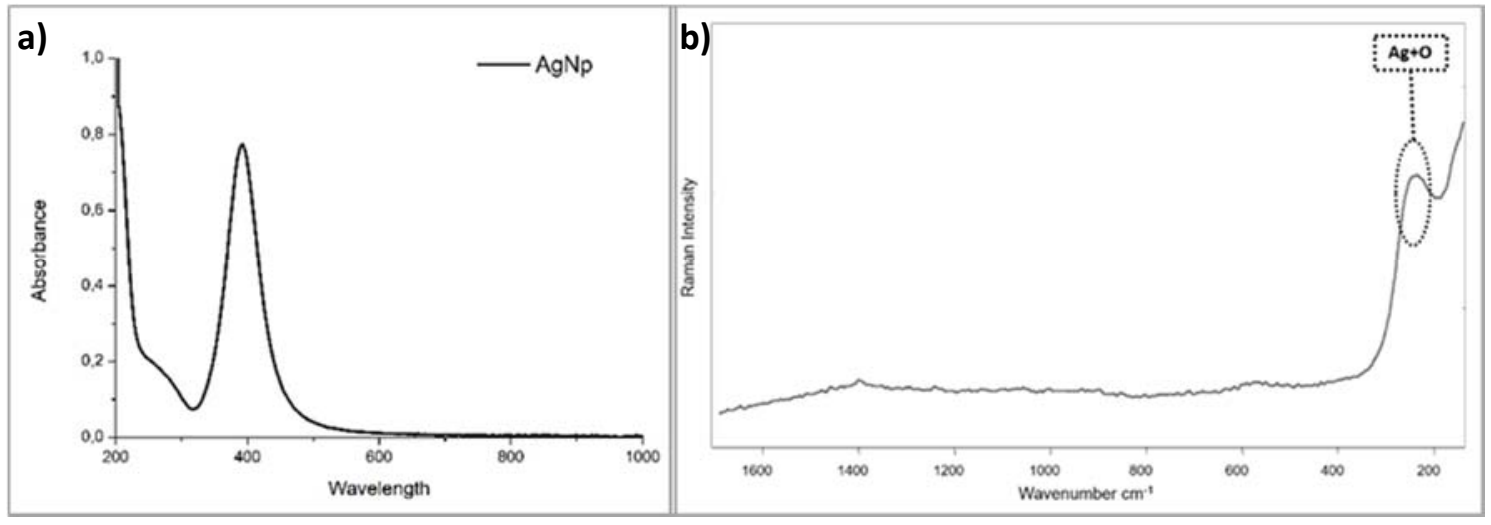

Figure 1. UV-Vis spectra (a) and Raman spectra (b) of the nanoparticles treatment. 


\subsection{Application of the treatment on limestones}

Figure 2 shows the limestone slabs before and after deposition of the treatment. The heterogeneity and porosity characteristic of the limestone matrix are clearly visible in the untreated slab. Magnified images of the stone surface display a homogeneous distribution of the treatment without the presence of aggregation nanoparticles in the surface slabs.

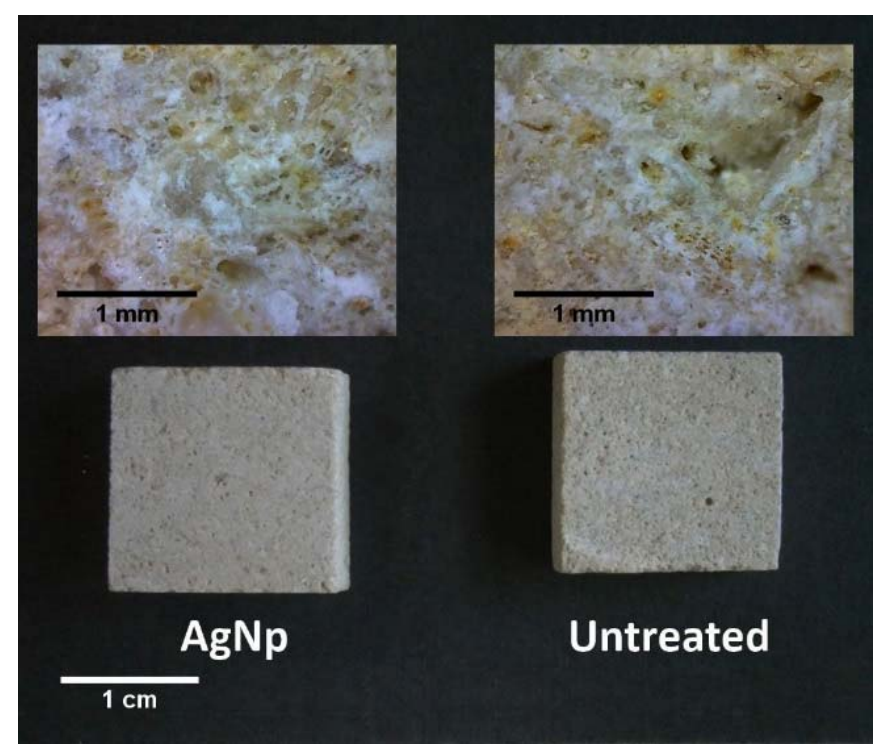

Figure 2. Digital photograph of limestone slabs before (untreated) and after the application of the treatment. Magnified stone surface images were analysed with a Zarbeco handheld digital microscope.

\subsection{Penetration of the treatment in the stone matrix}

The capability of LIBS technique for detecting the silver nanoparticles and for analyzing the penetration of the treatment in the limestone matrix has been tested in this study. Figure 3 shows the AgNPs sample before and after a LIBS analysis. As it can be seen, the generated crater measures less than $200 \mu \mathrm{m}$ in diameter and it is difficult to distinguish it from the pores and homogeneity changes of the sample, demonstrating the minimally invasive feature of the technique. 
a)

b)

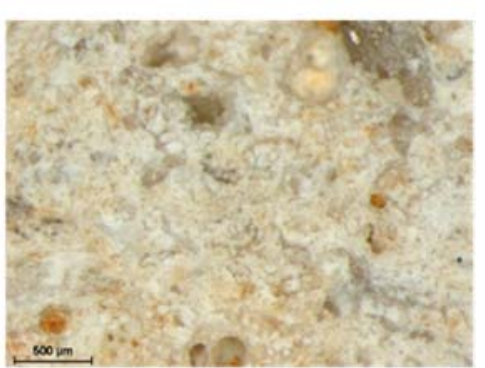

c)

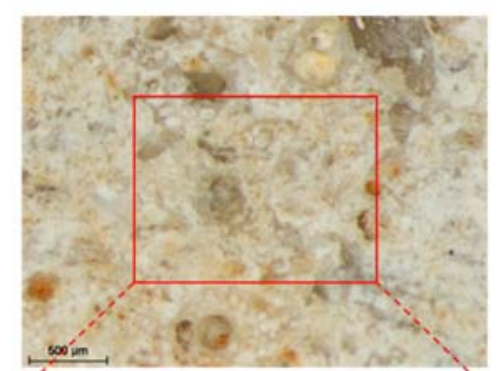

Figure 3. Photograph of a zoomed area from the AgNPs sample a) before the analysis, b) after the analysis and c) detail of the crater.

First, a detection test was performed in the AgNPs sample and also in the untreated sample for comparison. The results of this study are shown in Figure 4. LIBS spectra corresponding to the analysis of the slab treated with AgNPs and of the untreated sample are plotted in Figure 4a and Figure 4b, respectively. As shown, the peak corresponding to $\mathrm{Ag}$ (I) $338.289 \mathrm{~nm}$ emission line is clearly distinguished in the sample with silver nanoparticles while it does not appear in the spectrum from the untreated sample, where only peaks from the limestone are observed. This result demonstrates that LIBS technique is capable of detecting silver nanoparticles in the stone matrix in the concentration range used in the synthesis of the sample and adequate for bactericidal treatment $[10,11]$. It should be noted that the correct identification of the Ag peak in the spectrum of the AgNPs sample was also confirmed by comparing the spectrum from Figure $4 a$ to those obtained from pure silver reference samples. 
b)

)
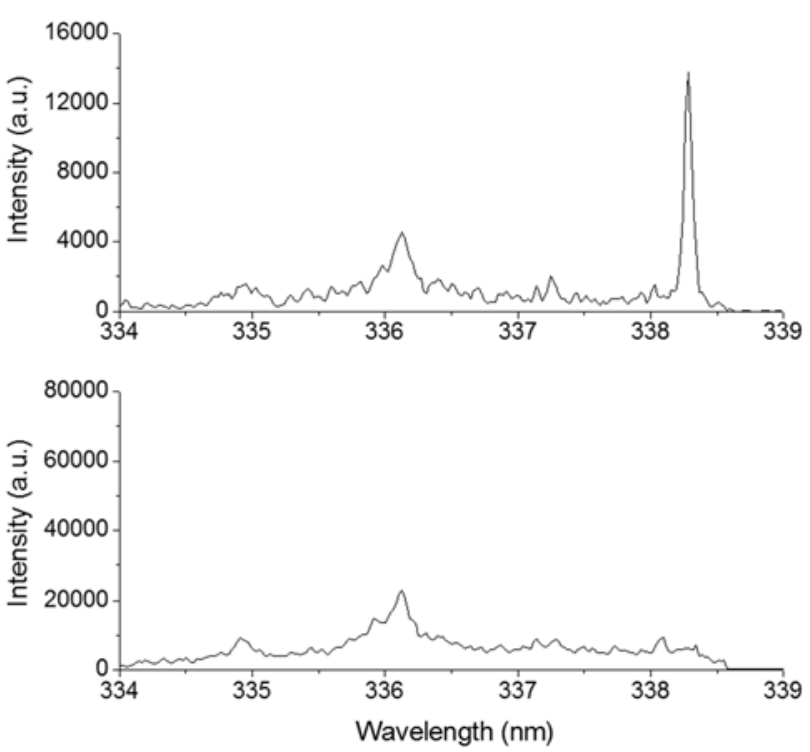

Figure 4. LIBS spectra a) AgNPs sample, b) untreated sample.

Once demonstrated the detection capability of LIBS technique for silver nanoparticles in limestone, the next step is to test if LIBS procedure is able to measure the penetration of the bactericidal treatment. For that purpose, depth analyses were performed in the sample under study by delivering several in-depth laser pulses at the same position to get spectral information of the sample composition at different depth levels. In this sense, depth-related spectra can be obtained by monitoring laser-induced plasma emission from each laser shot. Afterwards, a plot of the intensity of $\mathrm{Ag}$ (I) $338.289 \mathrm{~nm}$ emission line of the spectrum, characteristic of the silver nanoparticles, versus the number of laser pulses of the in-depth sequence, yields the LIBS depth profile. An example is shown in Figure 5, where a LIBS depth profile of Ag in the AgNPs sample is shown after being subjected to different types of signal processing for comparative purposes. First, the depth profile of the raw intensity of the peak corresponding to Ag (I) $338.289 \mathrm{~nm}$ emission line is shown in Figure $5 a$ without any data treatment. In Figure $5 b$, the depth profile has been generated by plotting the integrated area under the Ag peak instead of peak intensity. Then, two types of normalization procedures are carried out to the $\mathrm{Ag}$ signal and the associated depth profiles are shown in Figures $5 \mathrm{c}$ and $5 \mathrm{~d}$. Normalization is used to correct for shot-to-shot variations in the laser energy, spot size, and other experimental parameters such as matrix effects that can influence the temperature of the plasma and, as a consequence the emission intensity, during the LIBS analysis [42]. The first procedure, also called total light normalization, consists of dividing the intensity or the area of the emission peak of interest by the sum of the entire spectrum and it is sometimes used as an alternative in cases where the use of an internal standard is not possible [42]. The depth profile of Figure $5 \mathrm{c}$ has been generated after using this method and corresponds to the Ag peak intensity normalized to the total intensity of the spectrum. Finally, the last normalization procedure consisted of dividing the intensity of the $\mathrm{Ag}$ identified peak by the intensity of a peak from the same spectrum, used as an internal standard. In this study, the peak of $\mathrm{Ca}$ (I) at $558.197 \mathrm{~nm}$, characteristic of the limestone matrix, was employed as the internal standard and the depth profile generated with the normalized values 
is plotted in Figure $5 \mathrm{~d}$. It should be noted that analogous depth profiles were obtained when the normalization was carried out using other peaks of the matrix. When comparing the four depth profiles of Figure 5 no significant differences can be found. In this sense, except some fluctuation at low signal level, the profiles exhibit the expected decrease of the signal with the number of in-depth laser pulses in agreement with the diffusion of the silver nanoparticles treatment inside the stone matrix. The similarity of the four depth profiles of Figure 5 indicates that the fluctuation of the signal after the fifth pulse is not due to experimental facts, which could be partially counteracted by the use of normalization, but it is due to changes in the composition of the analyzed material, as desirable. Due to this fact, the simplest peak intensity method was selected for the following studies.

a)

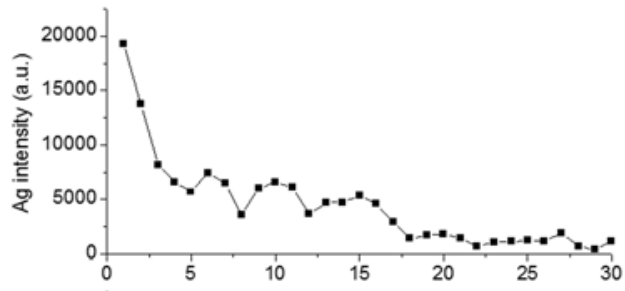

b)

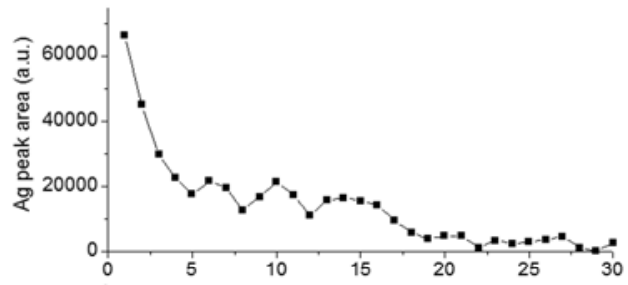

c)

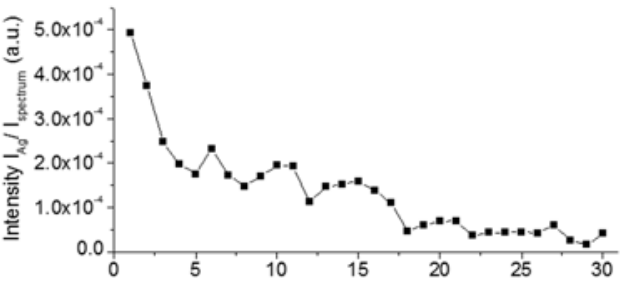

d)

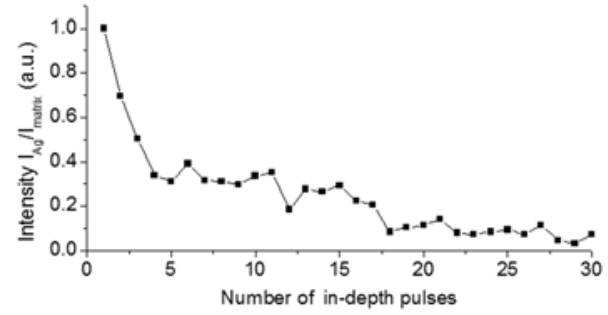

Figure 5. LIBS depth profile with different processing of Ag signal: a) Peak intensity, b) Peak area, c) Peak intensity normalized to the total intensity of the spectrum, d) Peak intensity normalized to the intensity of a peak from the matrix.

With the purpose of continuing the study of the capability of LIBS technique for in-depth characterization of the treated limestone, a reproducibility test was carried out. For that purpose, several in-depth analyses were performed in the AgNps sample by delivering 30 indepth laser pulses at the same position. These analyses were carried out under the same experimental conditions and in different regions of the sample surface in order to perform a representative sampling. Some results of this study are shown in the depth profiles of Figure 6. 
Although some small variations of the signal can be observed when comparing the profiles of Figure 6 each other, the trend of the four profiles is quite similar, exhibiting a decrease of $\mathrm{Ag}$ signal with depth, as expected. In this sense, the results are comparable and the Ag signal is almost negligible after the $20^{\text {th }}$ pulse, in all cases, indicating that the silver nanoparticles treatment has not reach that depth level. These results evince that LIBS technique is a good candidate for characterizing the penetration of bactericidal nanoparticles treatments. The small fluctuation of the signal in the depth profiles of Figure 6 can be related to the porosity and heterogeneity of the analyzed sample, as shown in Figures 2 and 3, which can affect the diffusion process of the AgNps treatment.

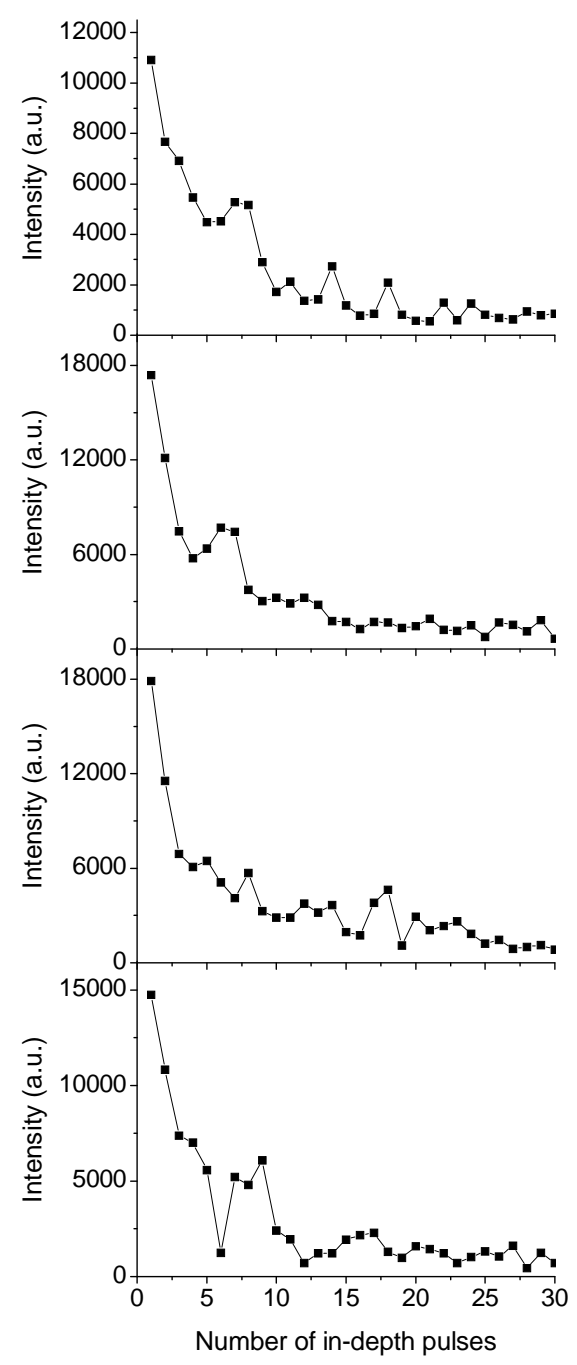

Figure 6. LIBS in-depth profiles of Ag signal in four different locations of AgNPs sample.

In order to quantify the penetration of the silver nanoparticles, the number of in-depth pulses or laser shots of the previous study must be substituted by depth. For the determination of the depth scale it is necessary to calculate the average ablation rate, that is, the depth eroded by each laser pulse [43]. For this purpose, several craters were generated in the AgNps sample by delivering a different number of in-depth laser pulses and their corresponding depth was measured using optical microscopy [44]. The ablation rate, calculated dividing the depth of the 
craters by the corresponding number of delivered laser pulses [45], resulted in an average value of $10 \mu \mathrm{m} /$ pulse. Using this value, the number of in-depth pulses at which the Ag signal disappeared was transformed into depth and the penetration of silver nanoparticles in the limestone was calculated for each LIBS in-depth analysis. The estimated values of penetration depth are included in Table I for eight replicated analyses. In order to take into account the possible variations of the treatment penetration between different locations, due to sample heterogeneity and porosity, the authors consider that the penetration results should be provided as a range. In this sense, from the data of Table I the estimated penetration range for silver nanoparticles in the limestone matrix resulted to be $130-230 \mu \mathrm{m}$, which is a depth reach adequate for protection against bacteria development.

\begin{tabular}{|c|c|}
\hline Number of analysis & Penetration $(\boldsymbol{\mu m})$ \\
\hline 1 & 180 \\
\hline 2 & 200 \\
\hline 3 & 160 \\
\hline 4 & 190 \\
\hline 5 & 130 \\
\hline 6 & 130 \\
\hline 7 & 230 \\
\hline 8 & 140 \\
\hline
\end{tabular}

Table I: Penetration values of AgNPs in the limestone slabs, estimated by LIBS in-depth analysis.

\section{Conclusions}

In this work, LIBS technique has been tested for the in-depth characterization of new nanomaterials to be employed in heritage buildings for protective purposes. The assessment of these nanomaterials depends on the depth penetration of the compound and, therefore, it is of great interest to characterize the location of these nanoparticles in the matrix. For this reason, the penetration into limestone stone matrices of a biocidal treatment based on citrate-stabilized silver nanoparticles (AgNps), which is known to be an effective protection against bacteria development, has been analyzed in this study by LIBS for the first time.

In a preliminary step, the LIBS spectra obtained from the sample treated with silver nanoparticles and also from an untreated sample have been compared and the identification of the characteristic emission peak of $\mathrm{Ag}$ in the treated sample has demonstrated the detection capability of the technique. Afterwards, several in-depth analyses have been performed by LIBS in different positions of the sample under study to characterize the diffusion of the bactericidal treatment in the limestone. Reproducible results have been obtained in that study and the generated LIBS depth profiles exhibit a decay of the Ag signal with the number of in-depth laser pulses, in agreement with the decrease of the treatment effect with depth, evidencing the usefulness of LIBS technique for the in-depth characterization of these nanomaterials. The 
normalization of the Ag signal in the depth profiles to the total intensity of the spectrum or to the intensity of an internal standard has not produced significant changes. This fact indicates that the small fluctuation of the signal in the depth profiles is not due to experimental factors but it is probably caused by the porosity and heterogeneity of the sample, which affects the nanoparticles diffusion process. From the depth at which the Ag signal disappeared in LIBS indepth analyses, the penetration of the AgNPs bactericidal treatment in the limestone slab was estimated as $130-230 \mu \mathrm{m}$. These values allow to evaluate the effectiveness of this type of treatment for protective purposes.

In conclusion, these preliminary results demonstrate the capability of LIBS technique for the detection of nanoparticles, for the generation of associate depth profiles which allow to analyse the nanoparticles diffusion in the matrix after the application of protective treatments in historical buildings and for the analysis of the penetration depth of this biocide treatment in order to determine its effectiveness. Additional studies are in progress to compare the penetration of different bactericidal treatments based on silver nanoparticles and nanocomposites.

\section{Acknowledgements}

This study has been partially supported by the projects: Art-Risk (RETOS project of Ministerio de Economía y Competitividad and Fondo Europeo de Desarrollo Regional (FEDER),code: BIA201564878-R (MINECO/FEDER, UE)), CTQ2013-48396-P of Fondo Europeo de Desarrollo Regional (FEDER-Unión Europea) and Ministerio Economía y Competitividad and the research teams P10FQM-6615, TEP-199 and FQM-319 from Junta Andalucía. J. Becerra is grateful to the Ministerio de Educación, Cultura y Deporte for his pre-doctoral fellowship (FPU14/05348) and to the University Ecclesiastical Academy of Thessaloniki for his stay as visiting researcher.

\section{References}

[1] A.M.M. Essa, M.K. Khallaf, Biological nanosilver particles for the protection of archaeological stones against microbial colonization, Int. Biodeterior. Biodegrad. 94 (2014) 31-37. doi:10.1016/j.ibiod.2014.06.015.

[2] R. Carrillo-González, M.A. Martínez-Gómez, M. del C.A. González-Chávez, J.C. Mendoza Hernández, Inhibition of microorganisms involved in deterioration of an archaeological site by silver nanoparticles produced by a green synthesis method, Sci. Total Environ. 565 (2015) 872-881. doi:10.1016/j.scitotenv.2016.02.110.

[3] P. Munafò, G.B. Goffredo, E. Quagliarini, TiO2-based nanocoatings for preserving architectural stone surfaces: An overview, Constr. Build. Mater. 84 (2015) 201-218. doi:10.1016/j.conbuildmat.2015.02.083.

[4] L. Graziani, E. Quagliarini, A. Osimani, L. Aquilanti, F. Clementi, C. Yéprémian, V. Lariccia, S. Amoroso, M. D'Orazio, Evaluation of inhibitory effect of $\mathrm{TiO} 2$ nanocoatings against microalgal growth on clay brick façades under weak UV exposure conditions, Build. Environ. 64 (2013) 38-45. doi:10.1016/j.buildenv.2013.03.003.

[5] I.D. van der Werf, N. Ditaranto, R.A. Picca, M.C. Sportelli, L. Sabbatini, Development of a 
novel conservation treatment of stone monuments with bioactive nanocomposites, Herit. Sci. 3 (2015) 29. doi:10.1186/s40494-015-0060-3.

[6] M. Rai, A. Yadav, A. Gade, Silver nanoparticles as a new generation of antimicrobials, Biotechnol. Adv. 27 (2009) 76-83. doi:10.1016/j.biotechadv.2008.09.002.

[7] J.S. Kim, E. Kuk, K.N. Yu, J.H. Kim, S.J. Park, H.J. Lee, S.H. Kim, Y.K. Park, Y.H. Park, C.Y. Hwang, Y.K. Kim, Y.S. Lee, D.H. Jeong, M.H. Cho, Antimicrobial effects of silver nanoparticles, Nanomedicine Nanotechnology, Biol. Med. 3 (2007) 95-101. doi:10.1016/j.nano.2006.12.001.

[8] B. Gutarowska, J. Skora, K. Zduniak, D. Rembisz, Analysis of the sensitivity of microorganisms contaminating museums and archives to silver nanoparticles, Int. Biodeterior. Biodegrad. 68 (2012) 7-17. doi:10.1016/j.ibiod.2011.12.002.

[9] F. Bellissima, M. Bonini, R. Giorgi, P. Baglioni, G. Barresi, G. Mastromei, B. Perito, Antibacterial activity of silver nanoparticles grafted on stone surface, Environ. Sci. Pollut. Res. 21 (2014) 13278-13286. doi:10.1007/s11356-013-2215-7.

[10] J. Becerra, A.P. Zaderenko, M.J. Sayagués, R. Ortiz, P. Ortiz, Synergy achieved in silverTiO 2 nanocomposites for the inhibition of biofouling on limestone, Build. Environ. (2018). doi:10.1016/j.buildenv.2018.05.020.

[11] J. Becerra, A.P. Zaderenko, P. Ortiz, Silver/dioxide titanium nanocomposites as biocidal treatments on limestones, Ge-Conservación. 11 (2017) 141-148.

[12] M.F. La Russa, A. Macchia, S.A. Ruffolo, F. De Leo, M. Barberio, P. Barone, G.M. Crisci, C. Urzì, Testing the antibacterial activity of doped $\mathrm{TiO} 2$ for preventing biodeterioration of cultural heritage building materials, Int. Biodeterior. Biodegrad. 96 (2014) 87-96. doi:10.1016/j.ibiod.2014.10.002.

[13] E. Quagliarini, F. Bondioli, G.B. Goffredo, A. Licciulli, P. Munafò, Self-cleaning materials on Architectural Heritage: Compatibility of photo-induced hydrophilicity of TiO2 coatings on stone surfaces, J. Cult. Herit. 14 (2013) 1-7. doi:10.1016/j.culher.2012.02.006.

[14] G. B, R.H. Van, B. L, R. V, A.S. S, Nanolime deposition in Maastricht limestone : backmigration or accumulation at the absorption surface ?, in: EMABM 2015 Proc. 15th Euroseminar Microsc. Appl. to Build. Mater. Delft, Netherlands, 17-19 June 2015, Delft University of Technology, Delft, 2015: pp. 77-86.

[15] F. Gherardi, A. Colombo, M. D'Arienzo, B. Di Credico, S. Goidanich, F. Morazzoni, R. Simonutti, L. Toniolo, Efficient self-cleaning treatments for built heritage based on highly photo-active and well-dispersible TiO2 nanocrystals, Microchem. J. 126 (2016) 54-62. doi:10.1016/j.microc.2015.11.043.

[16] F. Colao, R. Fantoni, P. Ortiz, M.A. Vazquez, J.M. Martin, R. Ortiz, N. Idris, Quarry identification of historical building materials by means of laser induced breakdown spectroscopy, X-ray fluorescence and chemometric analysis, in: Spectrochim. Acta - Part B At. Spectrosc., 2010: pp. 688-694. doi:10.1016/j.sab.2010.05.005.

[17] S. Awasthi, R. Kumar, G.K. Rai, A.K. Rai, Study of archaeological coins of different dynasties using libs coupled with multivariate analysis, Opt. Lasers Eng. 79 (2016) 2938. doi:10.1016/j.optlaseng.2015.11.005.

[18] L. Caneve, A. Diamanti, F. Grimaldi, G. Palleschi, V. Spizzichino, F. Valentini, Analysis of fresco by laser induced breakdown spectroscopy, Spectrochim. Acta - Part B At. Spectrosc. 65 (2010) 702-706. doi:10.1016/j.sab.2010.05.003.

[19] S. Guirado, F.J. Fortes, V. Lazic, J.J. Laserna, Chemical analysis of archeological materials in submarine environments using laser-induced breakdown spectroscopy. On-site trials in the Mediterranean Sea, Spectrochim. Acta - Part B At. Spectrosc. 74-75 (2012) 137143. doi:10.1016/j.sab.2012.06.032.

[20] S. Mahmood, S.A. Abbasi, S. Jabeen, M.A. Baig, Laser-induced breakdown spectroscopic studies of marbles, J. Quant. Spectrosc. Radiat. Transf. 111 (2010) 689-695. doi:10.1016/j.jqsrt.2009.11.012. 
[21] P. Ortiz, V. Antúnez, R. Ortiz, J.M.M. Martín, M.A.A. Gómez, A.R.R. Hortal, B. MartínezHaya, Comparative study of pulsed laser cleaning applied to weathered marble surfaces, Appl. Surf. Sci. 283 (2013) 193-201. doi:10.1016/j.apsusc.2013.06.081.

[22] P. Ortiz, V. Antunez, R. Ortiz, J.M. Ramírez, M.A. Gómez, M. Bethencourt, I. López, V. Piñón, M.P. Mateo, G. Nicolás, IV Congreso Latinoamericano de Conservación y Restauración de Metal, in: Grupo Español de Conservación (Ed.), IV Congr. Latinoam. Conserv. y Restauración Met., Madrid, 2013: pp. 41-48.

[23] M.S. Rakotonirainy, L. Caillat, C. Héraud, J.B. Memet, Q.K. Tran, Effective biocide to prevent microbiological contamination during PEG impregnation of wet archaeological iron-wood artefacts, J. Cult. Herit. 8 (2007) 160-169. doi:10.1016/j.culher.2007.01.005.

[24] A. De Giacomo, R. Gaudiuso, C. Koral, M. Dell'Aglio, O. De Pascale, Nanoparticleenhanced laser-induced breakdown spectroscopy of metallic samples., Anal. Chem. 85 (2013) 10180-10187. doi:10.1021/ac4016165.

[25] C. Koral, M. Dell'Aglio, R. Gaudiuso, R. Alrifai, M. Torelli, A. De Giacomo, NanoparticleEnhanced Laser Induced Breakdown Spectroscopy for the noninvasive analysis of transparent samples and gemstones, Talanta. 182 (2018) 253-258. doi:10.1016/j.talanta.2018.02.001.

[26] A. De Giacomo, M. Dell'Aglio, R. Gaudiuso, C. Koral, G. Valenza, Perspective on the use of nanoparticles to improve LIBS analytical performance: nanoparticle enhanced laser induced breakdown spectroscopy (NELIBS), J. Anal. At. Spectrom. 31 (2016) 1566-1573. doi:10.1039/C6JA00189K.

[27] L. Krajcarová, K. Novotný, M. Kummerová, J. Dubová, V. Gloser, J. Kaiser, Mapping of the spatial distribution of silver nanoparticles in root tissues of Vicia faba by laserinduced breakdown spectroscopy (LIBS), Talanta. 173 (2017) 28-35. doi:10.1016/j.talanta.2017.05.055.

[28] O. Picard, J.; Sirven, J.-B.; Sublemontier, On-line Monitoring of Nanoparticle Synthesis by Laser-Induced Breakdown Spectroscopy in Vacuum, MRS Adv. 2 (2017) 1487-1491. doi:10.1557/adv.2016.633.

[29] T. Amodeo, C. Dutouquet, F. Tenegal, B. Guizard, H. Maskrot, O. Le Bihan, E. Fréjafon, On-line monitoring of composite nanoparticles synthesized in a pre-industrial laser pyrolysis reactor using Laser-Induced Breakdown Spectroscopy, Spectrochim. Acta Part B At. Spectrosc. 63 (2008) 1183-1190. doi:10.1016/j.sab.2008.09.005.

[30] J. Menneveux, F. Wang, S. Lu, X. Bai, V. Motto-Ros, N. Gilon, Y. Chen, J. Yu, Direct determination of Ti content in sunscreens with laser-induced breakdown spectroscopy: Line selection method for high TiO2 nanoparticle concentration, Spectrochim. Acta Part B At. Spectrosc. 109 (2015) 9-15. doi:10.1016/j.sab.2015.04.010.

[31] F.C. De Lucia, A.W. Miziolek, K.L. Mcnesby, R.A. Walters, P.D. French, Laser-induced breakdown spectroscopy (LIBS) - an emerging eld-portable sensor technology for realtime, Sierra. (2005).

[32] D. Anglos, V. Detalle, Cultural Heritage Application of LIBS, in: Laser-Induced Break. Spectrosc., 2014: pp. 531-554. doi:10.1007/978-3-642-45085-3.

[33] C.Y. Flores, C. Diaz, A. Rubert, G.A. Benítez, M.S. Moreno, M.A. Fernández Lorenzo de Mele, R.C. Salvarezza, P.L. Schilardi, C. Vericat, Spontaneous adsorption of silver nanoparticles on $\mathrm{Ti} / \mathrm{TiO} 2$ surfaces. Antibacterial effect on Pseudomonas aeruginosa, J. Colloid Interface Sci. 350 (2010) 402-408. doi:10.1016/j.jcis.2010.06.052.

[34] M.Á. Bello López, Caracterización y estado de alteración química de los materiales empleados en la construción de la Catedral de Sevilla, Univerisdad de Sevilla, 1988.

[35] M.A. Guerrero, Diagnóstico del estado de alteración de la piedra del Palacio Consistorial de Sevilla. Causas y mecanismos, Universidad de Sevilla (Spain), 1990.

[36] P. Ortiz, M.A.A. Guerrero, M.A. Vázquez;, R. Ortiz;, J.M. Martin;, M.C.C. Peña, Accelerated weathering test as environmental behaviour trials on calcareous stone, in: Proc. XIth Int. Congr. Deterior. Conserv. Stone. I., Polonia, 2008: pp. 223-232. 
[37] P.K. Koutsoukos, P.G. Klepetsanis, N. Spanos, Calculation of Zeta-Potentials from Electrokinetic Data, in: P. Somasundaran (Ed.), Encycl. Surf. Colloid Sci., Taylor \& Francis Group, New York, 2006: pp. 1097-1113. doi:10.1081/E-ESCS-120000059.

[38] S. Kapoor, Preparation , Characterization , and Surface Modification of Silver Particles, Langmuir. 14 (1998) 1021-1025.

[39] D.C. Smith, C. Carabatos-Nedel, Raman Spectroscopy Applied to Crystals: Phenomena and Principles, Concepts and Conventions, in: I.R. Lewis, H. I G.M. Edwards (Eds.), Handb. Raman Spectrosc. From Res. Lab. to Process Line, Marcel Dekker, Inc., NewYork, Basel, 2001: pp. 349-422.

[40] N. Biswas, S. Kapoor, H.S. Mahal, T. Mukherjee, Adsorption of CGA on colloidal silver particles: DFT and SERS study, Chem. Phys. Lett. 444 (2007) 338-345. doi:10.1016/j.cplett.2007.07.049.

[41] A. Kora, S. Beedu, A. Jayaraman, Size-controlled green synthesis of silver nanoparticles mediated by gum ghatti (Anogeissus latifolia) and its biological activity, Org. Med. Chem. Lett. 2 (2012) 17. doi:10.1186/2191-2858-2-17.

[42] C.B. Stipe, B.D. Hensley, J.L. Boersema, S.G. Buckley, Laser-induced breakdown spectroscopy of steel: A comparison of univariate and multivariate calibration methods, Appl. Spectrosc. 64 (2010) 154-160. doi:10.1366/000370210790619500.

[43] M.P. Mateo, J.M. Vadillo, J.J. Laserna, Irradiance-dependent depth profiling of layered materials using laser-induced plasma spectrometry, J. Anal. At. Spectrom. 16 (2001) 1317-1321. doi:10.1039/b104440k.

[44] A. Casal, R. Cerrato, M.P. Mateo, G. Nicolas, 3D reconstruction and characterization of laser induced craters by in situ optical microscopy, Appl. Surf. Sci. 374 (2016) 271-277. doi:10.1016/j.apsusc.2015.11.249.

[45] M.P. Mateo, V. Piñon, G. Nicolas, Vessel protective coating characterization by laserinduced plasma spectroscopy for quality control purposes, Surf. Coatings Technol. 211 (2012) 89-92. doi:10.1016/j.surfcoat.2012.01.018. 